\title{
Lista delle abbreviazioni, delle biblioteche e degli archivi
}

\author{
ADV Archives départementales de Vaucluse \\ ASFi Firenze, Archivio di Stato \\ ASPo Prato, Archivio di Stato \\ BACT Toledo, Archivo y Biblioteca Capitulares \\ BAV Città del Vaticano, Biblioteca Apostolica Vaticana \\ BCA Perugia, Biblioteca Comunale Augusta \\ $\mathrm{BCl}$ Siena, Biblioteca Comunale degli Intronati \\ BL London, British Library \\ BML Firenze, Biblioteca Medicea Laurenziana \\ BM Firenze, Biblioteca Moreniana \\ BNB Milano, Biblioteca Nazionale Braidense \\ BNCF Firenze, Biblioteca Nazionale Centrale \\ BNCR Roma, Biblioteca Nazionale Centrale Vittorio Emanuele II \\ BNE Madrid, Biblioteca Nacional de España \\ BNF Paris, Bibliothèque Nationale de France \\ BR Firenze, Biblioteca Riccardiana \\ SPK Berlin, Staatsbibliothek Preussicher Kulturbesitz
}


